\title{
As perspectivas de Viktor Frankl e Erich Fromm sobre o amor e a humanidade
}

\author{
Viktor Frankl and Erich Fromm's perspectives on love and humanity \\ Las perspectivas de Viktor Frankl y Erich Fromm sobre el amor y la humanidad
}

Recebido: 05/08/2021 | Revisado: 09/08/2021 | Aceito: 10/08/2021 | Publicado: 14/08/2021

Flávio Luiz Honorato da Silva

ORCID: https://orcid.org/0000-0003-1307-3324

Universidade Federal da Paraíba, Brasil

E-mail: flavioluizh@yahoo.com.br

Ana Raquel Alencar Caldas

ORCID: https://orcid.org/0000-0003-3774-2887

Faculdade Três Marias, Brasil

E-mail: queelcaldas@gmail.com

Lucas Daniel Regis de Araújo

ORCID: https://orcid.org/0000-0002-3335-5268

Faculdade Três Marias, Brasil

E-mail: lucasdanielpsique@gmail.com

Leandro Honorato da Silva

ORCID: https://orcid.org/0000-0001-8269-8585

Universidade Paulista, Brasil

E-mail: 1honorato1@gmail.com

Sarah Xavier Vasconcelos de Fialho Rodrigues

ORCID: https://orcid.org/0000-0002-3101-5577 Faculdade Três Marias, Brasil

E-mail: sarah_xpv20@hotmail.com

Maria Gabriela Costa Ribeiro

ORCID: https://orcid.org/0000-0001-6920-9070

Faculdade Três Marias, Brasil

E-mail: mariagabicr@gmail.com

\begin{abstract}
Resumo
As perspectivas de pensamentos da Logoterapia e Análise Existencial de Frankl e a Psicanálise de Freud, apesar de visões diferentes de ser humano e mundo, há muito em comum, principalmente quando as influências do humanismo e existencialismo afetam os pensamentos de psicanalistas. Esse trabalho tem como objetivo apresentar os pressupostos teóricos sobre o amor e humanidade de Viktor Emil Frankl e Erich Fromm considerados dois humanistas. O artigo busca indicar, apesar das divergências entre as duas abordagens psicológicas, posições em comum principalmente semelhanças de pensamentos, ou seja, concordâncias de ideias em benefício de um bem comum da saúde mental do indivíduo na terapia. Foram utilizadas pesquisas bibliográficas em livros e artigos em bases de dados, por meio dos fundamentos teóricos dos pensamentos de Viktor Emil Frankl e de Erich Fromm. Averiguou-se que, mesmo de escolas divergentes em relação aos conceitos de ser humano e mundo, as duas abordagens apresentam, de acordo com os pensadores, perspectivas que convergem em relação aos construtos de amor e humanidade.
\end{abstract}

Palavras-chave: Logoterapia; Psicanálise; Autotranscendência; Sentido da vida; Visão humanista.

\begin{abstract}
The perspectives of thoughts of Frankl's Logotherapy and Existential Analysis and Freud's Psychoanalysis, despite different views of the human being and the world, there is much in common, especially when the influences of humanism and existentialism affect the thoughts of psychoanalysts. This work aims to present the theoretical assumptions about love and humanity of Viktor Emil Frankl and Erich Fromm, considered two humanists. The article seeks to indicate, regardless of the divergences between the two psychological approaches, common positions of similar thoughts, that is, agreement of ideas in benefit of a common good of the individual's mental health in therapy. Bibliographic research in books and articles in databases was used, through the theoretical foundations of the thoughts of Viktor Emil Frankl and Erich Fromm. It was found that, even from divergent schools in relation to the concepts of human being and world, the two approaches presented, according to the thinkers, perspectives that converge in relation to the constructs of love and humanity.
\end{abstract}

Keywords: Logotherapy; Psychoanalysis; Self-transcendence; Meaning of life; Humanist vision.

\section{Resumen}

Las perspectivas de los pensamientos de la logoterapia y análisis existencial de Frankl y el psicoanálisis de Freud, a pesar de las diferentes visiones del ser humano y el mundo, tienen mucho en común, especialmente cuando las influencias del humanismo y el existencialismo afectan los pensamientos de los psicoanalistas. Este trabajo tiene como objetivo presentar los supuestos teóricos sobre el amor y la humanidad de Viktor Emil Frankl y Erich Fromm, 
considerados dos humanistas. El artículo busca señalar, independientemente de las divergencias entre los dos enfoques psicológicos, posiciones comunes de pensamientos similares, es decir, concordancia de ideas en beneficio de un bien común de la salud mental del individuo en terapia. Se utilizó la investigación bibliográfica en libros y artículos en bases de datos, a través de los fundamentos teóricos del pensamiento de Viktor Emil Frankl y Erich Fromm. Se encontró que, incluso desde escuelas divergentes en relación a los conceptos de ser humano y mundo, los dos enfoques presentaban, según los pensadores, perspectivas que convergen en relación a los constructos del amor y la humanidad.

Palabras clave: Logoterapia; Psicoanálisis; Autotrascendencia; Significado de la vida; Visión humanista.

\section{Introdução}

Quando se estuda os pensamentos dos grandes pensadores da mente humana como Viktor Frankl e Erich Fromm é de vital importância apresentar, pelo menos, sucintamente as suas figuras humanas. A abordagem psicológica Logoterapia e Análise Existencial foram fundadas pelo médico psiquiatra, neurologista e doutor em filosofia Viktor Emil Frankl, que nasceu em Viena em 1905 e faleceu na mesma cidade em 1997. O pensamento desse autor influenciou e, neste tempo de pandemia e no pós pandemia necessitará das suas contribuições dada à ciência psicológica inspirará as gerações atuais e futuras relativa à filosofia, psicologia, sociologia, teologia, antropologia, pedagogia educacional, entre outras. Como afirmado por Silva et al. (2020):

Toda obra de Viktor E. Frankl é, para o atual Século XXI, uma proposta antropológica de dimensão copernicana, ou seja, uma reviravolta no pensamento psicológico mecanicista (a pessoa considerada mais como objeto do que como sujeito) para uma proposta que valoriza a dignidade do ser humano. É importante frisar que o pensamento de pessoa de Frankl é da ontologia dimensional (ser biopsicoespiritual) diferenciando dos pensamentos do Individualismo e do Materialismo, em função de preservar a humanidade e a dignidade do ser.

Na perspectiva da Logoterapia e Análise Existencial, considerada como $3^{\mathrm{a}}$ escola de psicoterapia vienense, o sentido da vida é a busca primária do ser humano na vida do dia a dia. Frankl foi discípulo de Freud (considerada a $1^{\text {a }}$ escola da psicologia vienense) e em seguida de Adler (considerada a $2^{\text {a }}$ escola da psicologia vienense). Ele sempre visualizou as genialidades de Freud e Adler, respeitando as importantes contribuições da Psicanálise e da Psicologia Individual no desenvolvimento da psicologia mundial. Mas afirmando que: "um anão sobre os ombros de um gigante pode dominar um campo visual maior que o gigante mesmo" (Frankl, 1967, p. 11), assim, julgava que era de vital importância extrapolar a visão psicológica do homem máquina para descobrir o Homo Humanus, isto é, humanizar a psicologia, retirando o psicologismo. A visão antropológica da logoterapia conceitua as dimensões biológica (somática), psicológica e noológica (espiritual). O noológico é entendido como sendo a dimensão dos fenômenos especificamente humanos, como o amor, a veneração, a ética e estética (Frankl, 2015).

O psicanalista Erich Fromm nasceu, na Alemanha de 1900, em berço de família judaica, assim como o pai da Psicanálise (Freud), tendo na famíliarabinos com grande tradição para os estudos da Torá. Iniciou seus estudos na psicanálise nos anos 20 , no Instituto de Psicanálise de Berlim, que à época era dirigido pelo médico e jurista Hanns Cachs. Nasceu em Frankfurt e faleceu em 1980 em Muralto (Suíça). Foi considerado além de psicanalista um grande psicólogo social e um profícuo escritor que se radicou nos Estados Unidos da América em 1934. Originalmente apresentou seus próprios pensamentos, inserindo na terapia noções de sociologia, tendo ciência da importância do impacto do meio social em que o indivíduo vive na saúde mental, contribuindo com a psicanálise na inclusão dos fatores econômicos e sociais na determinação do comportamento humano no meio em que vive. Erich Fromm foi considerado um humanista.

Esse trabalho tem como objetivo apresentar os pensamentos sobre o amor e humanidade de Viktor Emil Frankl e Erich Fromm considerados dois humanistas. O primeiro, fundador da abordagem Logoterapia e Análise Existencial, Psiquiatra e neurologista, e o segundo, discípulo de Freud, psicólogo e psicanalista. Busca-se apontar, apesar das divergências entre as duas abordagens psicológicas, pontos em comum principalmente semelhanças de pensamentos, ou seja, concordâncias de ideias em prol de um bem comum da saúde mental da pessoa na terapia. 


\section{Metodologia}

Esse artigo foi estruturado por meio de uma revisão da literatura baseado na metodologia de Koche (2011). Foram empregados os fundamentos teóricos do pensamento de Viktor Emil Frankl, fundador da Logoterapia e Análise existencial e do psicanalista e psicólogo social Erich Fromm que descreveram em seus trabalhos a compreensão do tema sobre o amor e humanidade. Foi utilizada da metodologia qualitativa descritiva reflexiva, com fundamento fenomenológico-existencial nas perspectivas das abordagens dos referidos autores, utilizando-se de levantamento bibliográfico (Medeiros et al., 2020, Silva et al., 2020, Silva et al., 2021a, Silva et al., 2021b).

\section{Resultados e Discussão}

Os resultados e discussão do presente trabalho são apresentados em formato de descrição e análise do material pesquisado na literatura, em configuração por itens.

\subsection{Amor e humanidade na perspectiva dos pensamentos de Frankl}

Para a visão da Logoterapia e Análise Existencial, o ser humano e os animais são compostos por dimensões biológica, psicológica e social, entretanto, o ser humano se distingue dos animais por ter uma dimensão noética (espiritual). Frankl se inspirou no filósofo Scheler (2003), mostrando que o ser humano não deixa as dimensões biopsíquicosocial, mas a essência de sua existência está na dimensão noética, sendo esta dimensão considerada superior, mais abrangente e inclui as outras dimensões, compondo a totalidade do ser humano (Frankl, 1991, 2019).

Para Frankl a inquietação primária de um ser humano não é prazer, felicidade, sucesso, poder ou reconhecimento, mas primariamente a vontade de assumir e realizar um sentido em sua vida. Ele destaca que "A verdade é que o amor é a meta última e mais alta a que pode aspirar o ser humano" (Frankl, 2019). Nos pressupostos da Logoterapia e Análise Existencial de Frankl, a autotranscendência é a verdadeira via que indica para satisfação da vontade de sentido, e o amor é o acesso para embrenhar nesta via de sentido da vida. Ele afirma que a essência da existência humana fixa-se na sua autotranscendência. "Ser homem significa, de per si e sempre, dirigir-se a ordenar-se a algo ou a alguém: entregar-se o homem a uma obra a que se dedica, a um homem a quem ama, ou a Deus a quem serve" (Frank1,2015).

Outra afirmação categórica de Frankl sobre o amor $(2008,136)$ :

Amor é a única maneira de captar outro ser humano no íntimo da sua personalidade. Ninguém consegue ter consciência plena da essência última de outro ser humano sem amá-lo. Por seu amor a pessoa se torna capaz de ver os traços característicos e as feições essenciais do seu amado; mais ainda, ela vê o que está potencialmente contido nele, aquilo que ainda não está, mas deveria ser realizado. Além disso, através do seu amar a pessoa que ama capacita a pessoa amada a realizar estas potencialidades. Conscientizando-a do que ela pode ser e do que deveria vir a ser, aquele que ama faz com que estas potencialidades venham a se realizar.

Para a Logoterapia e Análise Existencial a autrotranscendência é uma característica fundamental do homem, sendo o caminho para uma causa, uma tarefa a ser cumprida, um amor a uma pessoa além de si mesmo (não é ele mesmo), tendo como consequência a autorrealização da pessoa. A visão antropológica de Frankl conceitua as dimensões psicofísica e a noológica (espiritual)- onde está a dimensão dos fenômenos especificamente humana, como o amor, a veneração, a ética e estética (Frankl, 2011, 2015). Nestas perspectivas frankliana Jesus (2018) afirma que o ser humano deve, primariamente, viver buscando realizar planos e sentidos na vida, vivendo com vigor cada instante da vida, com cabal abertura ao que a vida possibilita como amor, esperança, alegria, sofrimento, perdas. 
Nesta perspectiva, o sentido pode se manifestar de três maneiras de valores: criativos, o que o ser humano faz pelo mundo como o trabalho ou um voluntariado, praticando uma ação para o outro; valores vivenciais ou experienciais, o que o ser humano recebe do mundo vivenciando como a união com o outro no amor, a natureza, a arte, a música, a filosofia, o belo, valores atitudinais e a atitude aceita diante do sofrimento inevitável (Aquino, 2013, Pacciolla, 2015, Jesus, 2018). Para Frankl (2008, 133) os valores são vividos concretamente pelo ser humano no dia a dia de sua existência:

Não se deve procurar um sentido abstrato da vida. Cada qual tem sua própria vocação ou missão específica na vida; é preciso executar uma tarefa concreta, que está a exigir realização. Nisso a pessoa não pode ser substituída, nem sua vida pode ser repetida. Assim, a tarefa de cada um é tão singular como a sua oportunidade específica de levá-la a cabo.

A perspectiva de Frankl sobre o amor alarga a importância para a melhor qualidade da vivência com sentido da existência humana, afirmando que o amor é uma capacidade essencialmente humana que tem seu foco na pessoa espiritual (noética), sendo o "amor um fenômeno humano no sentido exato da palavra. É um fenômeno especificamente humano, quer dizer: não se pode reduzir, sem mais, a um fenômeno sub-humano, nem de um fenômeno sub-humano se pode deduzir" (Santos, 2012). Continua o autor apresentando os pensamentos de Frankl que o amor é uma ação que qualifica a existência humana no que ela tem de humano, ou seja, uma ação existencial.

Segundo Santos (2012) a visão frankliana sobre o sentido do amor oferece uma perspectiva ontológica de elevação da importância a respeito do amor e, por intermédio do sentido do amor, um caminho possível de rehumanização das relações.

\subsection{Amor e humanidade na perspectiva dos pensamentos de Erich Fromm}

Segundo Fromm (1960) o ser humano produz coisas e ao realizá-lo, executa suas potencialidades sobre o mundo material. O Ser humano percebe o mundo em sua volta usando sua inteligência e se emocionando, utilizando-se do amor e pela razão. 'Seu poder de amor habilita-o a romper a muralha que o separa de outra pessoa e a compreender a esta" (Fromm, 1960, 92).

Na visão de Erich Fromm o que é o amor? Ele responde sucintamente que o amor é uma arte (amor fraterno, materno, erótico, amor-próprio, amor a Deus). O amor não é acidental, efeito do acaso, o amor é uma ação, uma posição prática, um ato da vontade. Bezerra (2020) afirma que para Erich Fromm o amor:

É sim algo que, na qualidade de arte, exige conhecimento e esforço. E como toda arte para ser vivida precisa ser aprendida - como na música, pintura, marcenaria, artes da medicina ou da engenharia - tal não poderia ser diferente com a atividade de amar, o que envolve, portanto, dois domínios que devem estar interpenetrados: o da teoria e o da prática.

Conforme entende Fromm (1960) as características básicas de todas as maneiras de amor são desvelo (dedicação), responsabilidade, respeito e conhecimento. Assim, as características de desvelo e responsabilidade evidencia que o amor é uma ação e não uma paixão que domine o ser humano, nem tão pouco uma afeição onde a pessoa é "contaminada". A responsabilidade, segundo o autor é uma resposta de um clamor que é ouvido, sendo a palavra responsabilidade da mesma raiz etimológica de resposta, ou seja, respondere (responder) - ser responsável é encontrar-se pronto a dar resposta (responder).

Para Fromm (1960) o exemplo mais pleno de significado para o amor por ser recheado de ações de desvelo e responsabilidade é o amor de mãe, sendo utilizado com símbolo do ápice de amor na religião e na arte. Fromm lembra que a palavra hebraica que designa o amor de Deus pelo ser humano e o amor de um ser pelo outro ser humano (amor ao próximo) é rachamim, sendo o radical desta palavra rechem que é igual a útero (órgão do aparelho genital feminino). Desta forma, para o autor, o amar a uma pessoa provoca o cuidado com a pessoa amada, o sentir responsável pela vida do amado em todas as 
dimensões (cuidados físicos, esforço no desenvolvimento de todos os potenciais da pessoa). O amar a uma pessoa é relacionarse com a essência humana, com todas as suas potencialidades, ou seja, todo o seu ser. O desvelo e a responsabilidade, como já dito anteriormente, são para Fromm elementos constitutivos do verdadeiro amor, mas sem os outros elementos, conhecimento e respeito da pessoa amada, este amor debilita e se torna dominação e possessividade, sendo o respeito "a capacidade de ver uma pessoa tal como é, de ter consciência de sua individualidade e originalidade. Não é possível respeitar alguém sem o conhecer; o desvelo e a responsabilidade seriam cegos se não fossem orientados pelo conhecimento da individualidade da pessoa" (Fromm, 1960, 96).

Assim, para Fromm o amor tem uma razão de acontecer, sendo uma necessidade vital do ser humano, pois as pessoas têm a necessidade de amar e ser amado. O amor demanda conhecimento e diligência. Sendo, o amor uma arte(música, pintura, dança, entre outras) para que seja vivido, necessita da ação, da doação, da responsabilidade, do cuidado, do respeito e do conhecimento.

Uma definição importante nas concepções de ser humano de Fromm (1960) é a orientação produtiva da personalidade que é referenciado como a capacidade do ser humano de empregar suas energias para realizar suas potencialidades inerentes, ou seja, a produtividade é uso de suas potencialidades. Para o autor "A produtividade é uma atitude de que todo ser humano é capaz, salvo se for inválido mental e emocionalmente" (Fromm, 1960, 82). Para ele, entre a concepção/nascimento e a morte do ser humano há o viver que é um mecanismo para realizar as potencialidades do indivíduo, para movimentar à vida "tudo o que lhe foi dado potencialmente nas duas células germinativas" (Fromm, 1960, 87).

A extirpação da atividade produtiva no ser humano enseja à inativação ou a atividade exorbitante (ativismo excessivo). A atividade produtiva é caracterizada pela ação do dia a dia e por momentos de repouso no trabalho. Ter momentos de repouso para ser capaz de ficar só consigo mesmo e escutar sua consciência, condição fundamental para o bom relacionamento com o outro. Deste pensamento, se apresenta a afirmação "O amor é um fenômeno de abundância; sua premissa é a força do indivíduo que pode dá-lo. O amor é afirmação e produtividade. Ele procura criar o que é amado. Amar outra pessoa só é uma virtude quando se origina dessa força interior” (Fromm, 1960, 117). Para Fromm, se é virtude amar o outro, é virtude também amar a si mesmo, pois não há nenhuma definição a respeito do ser humano que o eu não esteja incluso. Ele lembra a passagem bíblica: “Amarás o próximo como a ti mesmo". O amor ao outro e o amor a si mesmo está em todo ser humano capaz de amar, enquanto para Fromm, o egoísta não é capaz de amar o outro nem tampouco a si mesmo. Assim:

O amor genuíno é uma expressão de produtividade e implica desvelo, respeito, responsabilidade e conhecimento. Não é um "afeto" na acepção de se ser afetado por alguém, mas um anelo ativo pelo engrandecimento e felicidade da pessoa amada, arraigado na própria capacidade que se tem para amar...Assim como é mister conhecer-se outra pessoa e suas necessidades reais para se poder amá-la, também é preciso conhecer-se seu próprio eu para entender quais são os interesses deste e como poderão ser atendidos (Fromm, 1960, 120, 123).

\subsection{Concordância das perspectivas de Frankl e Fromm}

Segundo Andrade (2018) a importância de encaminhar o ser humano à consciência do sentido e dos valores é a principal divergência entre a logoterapia e a psicanálise freudiana, por Freud delinear os atos e valores humanos sob a ótica da libido. Mesmo com estasdiscordâncias, Frankl considerava legítimo e necessário o fato de que a psicanálise de Freud guia o indivíduo à consciência, ou seja, a instância de valores com responsabilidade, com os vínculos sociais e os instintos.

A visão humanista e da psiquiatria e psicologia existencial, tendo a filosofia como base, influenciou tanto Frankl como Fromm. Andrade (2018) afirma que para a abordagem humanista, apessoa é compreendida em seu conjunto (holisticamente).

Frankl (2019) afirma que o biologismo, o psicologismo e o sociologismo desrespeitam o espiritual, edificando ícones do ser humano que apresenta arremedo de humanidade, ou seja, vendo apenas os "ismos" o biologismo, psicologismo e sociologismo não há nenhuma via de acesso para o humanismo, mas para um simples homunculismo (ser humano desprezível). 
Fromm, em seus vários escritos, como o livro: “Análise do Homem” (Fromm, 1960) diverge do pensamento de Freud por seu biologismo e posiciona em seu local na análise psicológica componentes antropológicos, culturais e sociais, afirmando que a pulsão biológica que ele propõe no ser humano é a de viver e crescer. Os pensamentos de Fromm progridem a via psicanalítica, ou seja, considera uma das principais contribuições para a psicanálise por ir além da visão de Freud, que no espírito da época valorizava praticamente e apenas o fisiológico do ser humano, achando que o indivíduo é uma criatura supra instintiva (Viana, 2010). Desta forma Viana (2010) afirma:

A crítica do biologismo e pansexualismo é uma das partes mais profícuas da análise de Fromm, mostrando a importância da sociedade na constituição do ser humano e seu universo psíquico. O grande mérito de Freud foi à descoberta do inconsciente e a grande contribuição de Fromm foi à percepção da determinação social e cultural no universo psíquico.

São ideias que aproximam Frankl e Fromm em suas perspectivas de psicoterapias, em abordagens diferentes como Logoterapia e Análise existencial e psicanálise.Vejamos outras congruências dos pensamentos dos dois psicoterapeutas, tal como a Logoterapia e a psicanálise nos traz a comunicação de esperança no ser humano que apresenta potencialidade, onde Fromm afirma que a produtividade é uso de suas potencialidades e Frankl afirma semelhantemente que aquele que ama faz com que estas potencialidades venham a se realizar, efetivando, desta forma,o que é de importância no viver da pessoa que é o "dever ser" ("ser vir a ser"), exercendo com responsabilidade a liberdade do indivíduo, respondendo positivamente de frente as situações apontadas pela vida, sendo edificado no dia a dia do viver, nas ações concretas, o mais belo monumento da existência, em função do ser humano apresentaras potencialidade inerentes que Frankl e Fromm acreditam. Fromm reafirma que o ser humano sóbrio acredita nas potencialidades dos outros, de si mesmo e da humanidade, em função de ser uma pessoa que realiza o amor e suas potencialidades de viver com responsabilidade do viver bem.

Utilizando a ontologia dimensional de Frankl, segundo Santos (2012), que declara que o foco do indivíduo é espiritual, pode-se afirmar que para poder alcançar o alto valor do outro é de vital importância que primeiramente eu atinja este alto valor em mim mesmo, mesma concepção de Fromm em seus escritos: “Assim como é mister conhecer outra pessoa e suas necessidades reais para se poder amá-la, também é preciso conhecer-se seu próprio eu para entender quais são os interesses deste e como poderão ser atendidos" (Fromm, 1960, 123).

Fromm tece comentários sobre a liberdade como condição necessária do ser humano de viver bem, mas não no sentido da possibilidade de escolhas arbitrárias, mas sim para consolidar as potencialidades de realizar a verdadeira natureza do ser humano. Tendo Fromm o mesmo foco de pensamento, Frankl acrescenta em seus pressupostos teóricos que a liberdade é uma parte da moeda e metade da verdade. A outra metade da moeda é a responsabilidade, pois a liberdade sem a responsabilidade facilmente se degenera em arbitrariedade.

Santos (2012) relembra o ditado popular que "o amor é cego", visão não compartilhada nem por Frankl nem por Fromm em seus escritos, corroborando que o amor avista bem mais longe e a perspectiva da visão do ser humano em sua dignidade é alargada. $\mathrm{O}$ amor alarga a visão das potencialidades do outro amado.

Fromm (1960) concede o amor produtivo como a maneira mais íntima de relacionamento entre duas pessoas, sendo preservada a integridade individual dos amantes. Ele considera um fenômeno de abundância, e sua atividade é uma demonstração do amadurecimento do ser humano e como consequência deste amor se enche de alegria e felicidade. Frankl (2015) declara que o fundamento do homem é a autotranscendência, ou seja, sair do eu para o tu (um amor, uma tarefa) ou Tu (um Deus) e este sair gera uma felicidade (consequência).

No que concerne ao acreditar nas potencialidades do ser humano, Fromm e Frankl se coadunam nas ideias. A consciência para Fromm está fundamentado no julgar a conduta moral dos seres humanos, com abertura do conhecimento íntimo do indivíduo, conhecimento da arte de viver o dia a dia da pessoa. Ele afirma que a consciência é uma qualidade afetiva, por ser 
a reação da integralidade da personalidade e não somente da mente da pessoa. $\mathrm{O}$ autor utilizando sua definição de produtividade, afirma que quanto mais produtivo se vive, se faz mais forte a consciência e consequentemente se é mais produtivo na vida. Para ele a consciência é "a voz que o convoca de volta para si mesmo, permite-lhe saber o que deve fazer para se tornar ele mesmo e auxilia-o a permanecer a par das metas de sua vida e das normas necessárias à consecução dessas metas” (Fromm, 1960, 199). Frankl (2015) declara, o caráter de missão da vida e a convocação que o sentido da vida traz ao homem e nisso ele se constitui enquanto homem, sempre voltado para algo que não ele mesmo. Assim também é o sentido do amor, e nisso também constitui a humanização do homem, na medida em busca e realiza sentidos.

\section{Considerações Finais}

A principal contribuição do artigo é apresentar as concordâncias de dois pensamentos de escolas psicológicas com conceitos de pessoa e mundo diferentes que se coadunam com as visões de amor e humanidade. A logoterapia e análise existencial é centrada nos fenômenos especificamente humanos, com o alargamento da dimensão espiritual, ausente na psicanálise clássica que fica no biopsíquico. A abordagem da logoterapia centra no sentido da vida da pessoa, na intencionalidade, no senso valorativo (ético e estético), enquanto a psicanálise centra no inconsciente da pessoa. Fromm é da escola psicanalista americana, que tem influências dos pensamentos da filosofia humanistas.

Visualizando as contribuições para trabalhos futuros, pode-se buscar outros estudiosos da psicologia, que mesmo em abordagens diferentes, apresentam muitos pensamentos sobre o ser humano convergentes.

\section{Referências}

Andrade, C. J. (2018). Viktor Frankl: o sentido da Logoterapia e sua atualidade contextual. Psicólogo in Formação ano 21-22,.

Aquino, T. A. A. (2013). Logoterapia e análise existencial: uma introdução ao pensamento de Viktor Frankl. Editora Paulus.

Bezerra, V. (2010). Erich Fromm e a arte de amar. Revista Espaço Acadêmico, 110.

Frankl, V. E. (1967). Psicoanálisis y existencialismo. México: Fondo de Cultura Económica.

Frankl, V. E. (1991). A psicoterapia na prática. Papirus.

Frankl, V. E. (2008). Em busca de sentido. Um psicólogo no campo de concentração. (33a ed.), Ed. Sinodal, Ed. Vozes.

Frankl, V. E. (2011). A vontade de sentido: fundamentos e aplicações da logoterapia. Ed. Paulus.

Frankl, V. E. (2015). O sofrimento de uma vida sem sentido: caminhos para encontrar a razão de viver. Ed. É Realizações.

Frankl, V. E. (2019). A psicoterapia na prática. Ed. Vozes.

Fromm, E. (1960). Análise do Homem. Círculo do Livro.

Jesus, L. M. (2018). Qual é o sentido? reflexões sobre o sentido da vida a partir de Viktor Frankl. EDIPUCRS.

Koche, J. C. (2011). Fundamentos de metodologia científica. Vozes. http://www.brunovivas.com/wp-content/uploads/sites/10/2 018/07/K\%C3\%B6cheJos\%C3\%A9-Carlos0D0AFundamentos-de-metodologia-cient\%C3\%ADfica-_teoria-da0D0Aci\%C3\%AAncia-einicia\%C3\%A7\%C3\%A3o-\%C3\%A0pesquisa.pdf.

Medeiros, A. Y. B. V., Pereira, E. R., Silva, R. M. C. R. A., Dias \& F. A. (2020). Fases psicológicas e sentido da vida em tempos de isolamento social por pandemia COVID-19 uma reflexão a luz de Viktor Frankl. Research, Society and Development, 9(5). http://dx.doi.org/10.33448/rsd-v9i5.3131.

Pacciolla, A. (2015). Psicologia contemporânea e Viktor Frankl: Fundamentos para uma psicoterapia existencial. Editora Cidade Nova.

Santos, E. (2012). Em busca do amor. Monografia apresentada ao Curso de Especialização em Análise Existencial e Logoterapia de Viktor Frankl da Pontifícia Universidade Católica do Paraná, como requisito à obtenção do título de Especialista.

Scheler, M. (2003). A diferença essencial entre o homem e o animal. In: A posição do homem no cosmos. Editora Forense Universitária.

Silva, F. L. H., Assis, M. D., Durand, T. P., Santos, E. N. M., Honorato, M. C. M., \& Pontes, A. de M. (2020). Envelhecimento e sentido da vida na perspectiva de Viktor E. Frankl. Research, Society and Development, 9(11), e38591110068, 10.33448/rsd-v9i11.10068. 
Research, Society and Development, v. 10, n. 10, e403101019120, 2021

(CC BY 4.0) | ISSN 2525-3409 | DOI: http://dx.doi.org/10.33448/rsd-v10i10.19120

Silva, F. L. H., Assis, M. D. de, Honorato, M. C. M. \& Pontes, A. de M. (2021a). Educação tecnológica e em valores na perspectiva de Viktor Frankl. Research, Society and Development, 10 (1), e23910111690, 10.33448/rsd-v10i1.11690.

Silva, F. L. H., Simões, R. F. M., Queiroz, R. S. P. \& Pontes, A. de M. (2021b). O sentido do trabalho do docente universitário: reflexões para o pós-pandemia à luz do pensamento de Viktor Frankl. Research, Society and Development, 10 (2), e36010212655, 10.33448/rsd-v10i2.12655.

Viana, N. S. (2010). Fromm crítico de Freud. Revista Espaço Acadêmico, 110. 